\title{
Embryonic diapause in humans: time to consider?
}

\author{
Grazyna E Ptak ${ }^{1,2^{*}}$, Jacek A Modlinski ${ }^{2}$ and Pasqualino Loi ${ }^{1}$
}

\begin{abstract}
Background: When a competent blastocyst stage embryo finds itself in an unreceptive uterus, it delays development. In around one hundred species representing various orders, this delay is known to be reversible, but this phenomenon - termed embryonic diapause (ED) - is not considered a general characteristic of all mammals.

Presentation of the hypothesis: Recently, however, we demonstrated that a non-diapausing species, the sheep, is capable of ED, suggesting the hypothesis that this is in fact an ancestral trait common to all mammals, including humans.

Testing the hypothesis: In spite of the obvious difficulties in testing this idea, we propose a combination of indirect observations on human fertility patients, and direct study of the embryos of non-human primates.

Implications of the hypothesis: Support for our hypothesis would require revision of obstetric interventions routinely performed when a human pregnancy extends beyond the due date.
\end{abstract}

Keywords: Embryo, Delayed implantation, Embryonic diapause

\section{Background}

Before implantation in the uterus, an embryo develops on its own. Once it reaches the blastocyst stage, however, its metabolism slows down naturally, and in the absence of appropriate stimuli from the uterus, it will not develop further [1]. The receptivity of the uterus may be blocked in response to unfavourable conditions for pregnancy, including metabolic, climatic or even psychosocial conditions [2-4]. In some mammalian orders, such as Carnivora, Rodentia or Diprotodontia, which often encounter harsh climate and face undernutrition or metabolic stress due to lactation, such situations occur quite frequently, and therefore the embryo present in the uterus enters diapause (Table 1). ED is a protective phenomenon. As such, it represents an important developmental advantage for species survival, and thus should be evolutionally maintained. Indeed, in other species (so called non-diapausing), an unreceptive uterus does not always result in the immediate failure of the blastocyst. In rodents [5], pigs [6], rabbits [7] and horses [8], for example, transferring the embryo into an unreceptive surrogate female can still result in a successful pregnancy.

\footnotetext{
*Correspondence: gptak@unite.it

'Department of Comparative Biomedical Sciences, University of Teramo, Piazza A. Moro, Teramo 64100, Italy

${ }^{2}$ Department of Experimental Embryology, Institute of Genetics and Animal Breeding of the Polish Academy of Sciences, Jastrzebiec, Poland
}

In spite of these observations, the phenomenon of diapause, in which an embryo stops development but remains viable for an extended period, was assumed to be rare in mammals. We recently demonstrated that diapause may be displayed by embryos of domestic sheep [9]. We were similarly successful in observing ED in rabbit and cow blastocysts following their transfer to unreceptive mouse uteri [Modlinski \& Ptak, 2012, unpublished results]. Based on these observations, we hypothesize that ED is an ancient embryonic trait conserved across mammals, including humans. There are several lines of evidence indicating that this hypothesis needs to be taken seriously.

In animals, ED is usually the consequence of physiological stressors (photoperiod, lactation), while psychological stress is less likely to occur. In humans, conversely, the main cause of delayed implantation is related to psychological stress and smoking marijuana or nicotine [10-12]. All the aforementioned physiological and psychological stressors act through the hypothalamic-pituitarygonadal (HPG) axis, leading to luteal dysfunction and, as a consequence, altering uterine receptivity, as well as through the hypothalamic-pituitary-adrenal (HPA) axis, directly blocking the receptivity of the uterus $[4,10,12]$. The mechanism of this block is similar in all species: high level of glucocorticoids is produced as a response to the stressor [13]. These hormones, in turn, mediate 
Table 1 Examples of embryonic diapause in placental mammals

\begin{tabular}{|c|c|c|c|c|}
\hline Taxonomy & & Species & Gestation lenght & Embryonic diapause lenght \\
\hline Order: Chiroptera & Family: Pteropodidae & African fruit bat (Eidolon helvum) & 7-8 months & $3-4$ months \\
\hline \multirow[t]{13}{*}{ Order: Carnivora } & Family: Mustelidae & Sable (Martes zibellina) & Up to 290 days & 8 months \\
\hline & & Fisher (Martes pennati) & $10-12$ & 9-11 months \\
\hline & & North american river otter (Lontra canadensis) & 10-13 months & 8-11 months \\
\hline & & Short-tailed weasel (Mustela erminea) & 9-10 months & 8-9 months \\
\hline & & Long-tailed weasel (Mustela frenata) & 8 months & 7 months \\
\hline & & American mink (Neovison vison) & 40-75 days & $8-45$ days \\
\hline & & American badger (Taxidea taxus) & 8-9 months & 6-7 months \\
\hline & & European badger (Meles meles) & 4-12 months & 2-10 months \\
\hline & Family: Ursidae & Black bear (Ursus americanus) & 7-8 months & 5-6 months \\
\hline & & Brown bear (Ursus arctos) & 8 months & 6 months \\
\hline & & Giant panda (Ailuropoda melanoleuca) & $100-150$ days & 50-100 days \\
\hline & Superfamily: Pinnipedia & Northern fur seal (Callorhinus ursinus) & 1 year & 4 months \\
\hline & & Walrus (Odobenus rosmarus) & 15-16 months & 3-4 months \\
\hline \multirow[t]{2}{*}{ Order: Cingulata } & Family: Dasypodidae & Nine-banded armadillo (Dasypus novemcinctus) & 7-8 months & 3-4 months \\
\hline & & Seven-banded armadillo (Dasypus septemcinctus) & 6-8 months & 2-4 months \\
\hline Order: Artiodactyla & Family: Cervidae & Roe dear (Capreolus capreolus) & 10 months & 4-5 months \\
\hline
\end{tabular}

the down regulation of gonadotropins. Because gonadotropins are essential for the establishment of uterine receptivity, the implantation of the embryo is compromised whenever the maternal organism is under the action of the stressor [14-16].

In unreceptive human and mouse uteri, the concentration of anandamide (AEA) (an endogenous cannabinoid identified as a result of studies on the effects of $\Delta^{9}$-tetrahydrocannabinol, the active constituent of marijuana) increases sharply (reviewed in 10). As shown in a diapausing species, the mouse, as well as in a "non-diapausing" one, the sheep, AEA triggers reversible arrest of the embryo by binding to the cannabinoid receptors on the blastocyst $[10,17]$. AEA participates in the modulation of emotions and anxiety [18]. Therefore, augmented levels of cannabinoids in the human uterus, secreted in response to emotional stress (or due to smoking marijuana), may render implantation impossible. ED might be a natural consequence of such influences.

Delayed implantation was reported in humans long ago [19,20]. Wilcox et al. [1999] associated delayed implantation in humans with adverse pregnancy outcome, although the specific causes of pregnancy losses in their study were not evaluated [19]. Surprisingly and conversely to that human study, in animals delayed implantation appears to enhance the developmental potential of the embryo, as shown in rodents [5], pigs [6], rabbits [7] and sheep [21]. This increased developmental potential of mammalian embryos undergoing ED may be due to their cellular repair while being arrested (discussed in 9).
Therefore, how can the increased number of miscarriages reported following delayed implantation in humans be explained [19]? We hypothesize that it is because those patients were also under stress post implantation. In such circumstances, the implanted conceptus, being unable to display ED any longer, is damaged by unfavourable uterine conditions, and the pregnancy will end in miscarriage. Such a situation is less likely to occur in animals, in which once lactation or a season unfavourable for pregnancy progression ends, the embryo develops without further disturbance. Notably, more recent human studies refuted the association of delayed implantation with pregnancy loss [22].

\section{Presentation and testing of the hypothesis}

Although it has previously been suggested that ED might occur in humans [20,23], it has not been possible to test it experimentally, primarily because of ethical considerations. We propose two practical approaches that would allow this hypothesis to be explored further: indirectly, through an observational study on volunteer patients attempting to conceive (Study 1), and directly, using non-human primates (Study 2). A large-scale Study 1 on human patients, conducted along the lines of earlier studies [19], would provide valuable data on the precise timing of implantation in relation to stress exposure. Patients would daily collect first urine specimens to identify the day of ovulation (estrogen and progesterone metabolites), and subsequently of implantation (hCG). Patients would also periodically provide blood samples to allow measurement of stress hormones. In addition, 
they would complete a detailed questionnaire in relation to stressors to which they are exposed, in the family or the work place. Stress exposure would be periodically evaluated until the third month of gestation. Pregnancy outcome will be analyzed at term, using routine neonatal tests (APGAR). Patients should be divided into 3 groups:

1) Delayed Implantation ( $\geq 11$ days post ovulation), maternal stress confined to pre implantation, or no stress detected

2) Delayed Implantation ( $\geq 11$ days post ovulation), maternal stress extended to post implantation

3) Implantation on time (days $8-10$ post ovulation), no stress detected - control

The comparison of groups 1 and 3 will reveal if/how the delayed implantation influences the outcome of pregnancy. Furthermore, the comparison of groups 1 and 2 will allow the verification of if/how stress acting subsequently to delayed implantation may influence further pregnancy.

Direct confirmation of ED may be performed using non-human primates (Study 2), by studying the effects of a variety of experimentally induced stressors on implantation timing. In non-human primates (macaques or others) unreceptivity of the uterus should be induced during blastocyst development, expansion and attachment to the uterine wall (days $5-12$ post coitus) by using endocannabinoids treatment (simulating marihuana smoking) or by inducing stress (for example social stress by overcrowding of animals). Then, similar to study 1 analysis of hormones level (in urine or in blood) should be performed in order to evaluate the day of implantation. A part of unimplanted diapausing blastocysts should be surgically flushed from the uterus and subjected to detailed analysis to improve our understanding of their molecular and functional characteristics. Other blastocysts should be allowed to implant and carried to term so as to evaluate the consequences of ED on foetal development.

\section{Implications of the hypothesis}

If based on a reasonably high number of pregnancies, both studies ( 1 and 2) will address not only whether ED is a feature of human pregnancy, but also whether it is beneficial or harmful for pregnancy progression. If human embryo is able to enter diapause, this has huge implications for human pregnancy. If proven, the existence of human embryo diapause could question the adequacy of common gynecological practices, such as the estimation of the gestational age based on the last menstrual cycle or the stimulation of parturition. This hypothesis, if confirmed, would have a great impact on human reproductive medicine, opening up a fertile new investigation into the benefits or otherwise of ED in humans. Accordingly, common obstetric definitions, such as "foetus small for gestational age" or "prolonged pregnancy" may need to be revised. If ED occurs in humans, the current arbitrary use of day of last menstrual period to estimate ovulation and pregnancy duration will inevitably be misleading. The measure of effective date of implantation through a simple pharmaceutical device similar to those that currently measure hCG concentration would be of immense value, helping to reduce the uncertainty of overdue dates and to prevent unnecessary surgical interventions. Such tests should be done at least in those pregnancies in which the risk of complication or of reduced foetal growth is high, such as those obtained by assisted reproduction. Furthermore, if the developmental potential of the embryo may be enhanced by ED, undergoing diapause by embryos obtained by assisted reproduction (for example by their asynchronous transfer) may be suggested as a therapeutic approach. Furthermore, from the socio-economic point, the knowledge about this phenomenon may change cultural life-styles of the couples particularly around the time of embryo conception and implantation. Indeed the importance of the maternal contribution to the first phase of pregnancy (i.e. to periimplantation period) are often underestimated.

\section{Competing interests}

The authors declare that they have no competing interests.

\section{Authors' contributions}

GEP concived the study and wrote the manuscript. JAM and PL participated in its design and helped to draft the manuscript. All authors read and approved the final manuscript.

\section{Acknowledgments}

This work was supported by the European Research Council/Programme IDEAS (FP7/2007-2013, GA no. 210103) to G.E.P. This study was also partially financed by the IGAB PAS project (S.III. 1.3).

Received: 24 April 2013 Accepted: 11 September 2013

Published: 17 September 2013

\section{References}

1. Leese HJ, Baumann CG, Brison DR, McEvoy TG, Sturmey RG: Metabolism of the viable mammalian embryo: quietness revisited. Mol Hum Reprod 2008, 14:667-672.

2. Renfree MB: Embryonic diapause in marsupials. J Reprod Fertil 1981, 29:67-78.

3. Sandell M: The evolution of seasonal delayed implantation. Q Rev Biol 1990, 65:23-42.

4. Kondoh E, Okamoto T, Higuchi T, Tatsumi K, Baba T, Murphy SK, Takakura K, Konishi I, Fujii S: Stress affects uterine receptivity through an ovarianindependent pathway. Hum Reprod 2009, 24:945-953.

5. McLaren A, Michie D: Studies on the transfer of fertilized mouse eggs to uterine fostermothers. Factors affecting the implantation and survival of native and transferred eggs. J Exp Biol 1956, 33:394.

6. Wilde MH, Xie S, Day ML, Pope WF: Survival of small and large littermate blastocysts in swine after synchronous and asynchronous transfer procedures. Theriogenology 1988, 30:1069-1074.

7. Joung SY, Kim HJ, Choi WS, Im KS, Lee SH, Park CS, Jin DI: Effects of transferring in vitro-cultured rabbit embryos to recipient oviducts on mucin coat deposition, implantation and development. Zygote 2004, $12: 215-219$ 
8. Wilsher S, Clutton-Brock A, Allen WR: Successful transfer of day 10 horse embryos: influence of donor-recipient asynchrony on embryo development. Reproduction 2010, 139:575-585.

9. Ptak GE, Tacconi E, Czernik M, Toschi P, Modlinski JA, Loi P: Embryonic diapause is conserved across mammals. PLoS One 2012, 7:e33027. doi:10.1371/journal.pone.0033027.

10. Dey SK, Lim H, Das SK, Reese J, Paria BC, Daikoku T, Wang H: Molecular cues to implantation. Endocr Rev 2004, 25:341-373.

11. Jukic AM, Weinberg CR, Baird DD, Wilcox AJ: The association of maternal factors with delayed implantation and the initial rise of urinary human chorionic gonadotrophin. Hum Reprod 2011, 26:920-926.

12. Campagne DM: Should fertilization treatment start with reducing stress? Hum Reprod 2006, 21:1651-1658.

13. Arck P, Hansen PJ, Mulac Jericevic B, Piccinni MP, Szekeres-Bartho J: Progesterone during pregnancy: endocrine-immune cross talk in mammalian species and the role of stress. Am J Reprod Immunol 2007, 58:268-279.

14. Nagy GM, Bodnár I, Bánky Z, Halász B: Control of prolactin secretion by excitatory amino acids. Endocrine 2005, 28:303-308.

15. Webster Marketon Jl, Glaser R: Stress hormones and immune function. Cell Immunol 2008, 252:16-26.

16. Parker VJ, Douglas AJ: Stress in early pregnancy: maternal neuroendocrine-immune responses and effects. J Reprod Immunol 2010, 85:86-92.

17. Turco MY, Matsukawa K, Czernik M, Gasperi V, Battista N, Della Salda L, Scapolo PA, Loi P, Maccarrone M, Ptak G: High levels of anandamide, an endogenous cannabinoid, block the growth of sheep preimplantation embryos by inducing apoptosis and reversible arrest of cell proliferation. Hum Reprod 2008, 23:2331-2338.

18. Kathuria S, Gaetani S, Fegley D, Valiño F, Duranti A, Tontini A, Mor M, Tarzia G, La Rana G, Calignano A, Giustino A, Tattoli M, Palmery M, Cuomo V, Piomelli D: Modulation of anxiety through blockade of anandamide hydrolysis. Nat Med 2003, 9:76-81.

19. Wilcox AJ, Baird DD, Weinberg CR: Time of implantation of the conceptus and loss of pregnancy. N Engl J Med 1999, 340:1796-1799.

20. Grinsted J, Avery B: A sporadic case of delayed implantation after in-vitro fertilization in the human? Hum Reprod 1996, 11:651-654

21. Nepomnaschy PA, Weinberg CR, Wilcox AJ, Baird DD: Urinary hCG patterns during the week following implantation. Hum Reprod 2008, 23:271-277.

22. Lohstroh P, Dong H, Chen J, Gee N, Xu X, Lasley B: Daily immunoactive and bioactive human chorionic gonadotropin profiles in periimplantation urine samples. Biol Reprod 2006, 75:24-33.

23. Tarín JJ, Cano A: Do human concepti have the potential to enter into diapause? Hum Reprod 1999, 14:2434-2436.

doi:10.1186/1477-7827-11-92

Cite this article as: Ptak et al:: Embryonic diapause in humans: time to consider?. Reproductive Biology and Endocrinology 2013 11:92.

\section{Submit your next manuscript to BioMed Central and take full advantage of:}

- Convenient online submission

- Thorough peer review

- No space constraints or color figure charges

- Immediate publication on acceptance

- Inclusion in PubMed, CAS, Scopus and Google Scholar

- Research which is freely available for redistribution

Submit your manuscript at www.biomedcentral.com/submit
Ciomed Central 